\title{
Comparison of Surgically Inducedastigmatism Between Phacoemulsification and Small Incision Cataract Surgery at Tripoli Medical Center
}

Authors: Gamal Ali Bennaser, Ghareeb Albaggdadi Mansur Janeef

Department of Ophthalmology, Faculty Of Medicine, Tripoli University -2021

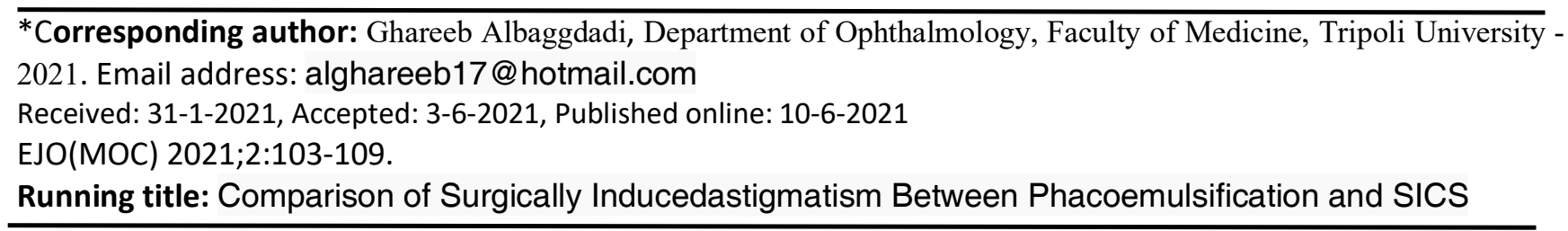

\section{Abstract}

Background: Surgically induced astigmatism is that the reason for poor postoperative vision even after uneventful cataract surgery.

Aim: The aim of study is to check the incidence, degree, type, and course of surgically induced astigmatism and visual sense in temporal 3.5-mm clear corneal phacoemulsification and 6-mm superior scleral incision in Small incision cataract surgery (SICS) at Tripoli medical center.

Materials and Methods: A total of 200 eyes of 200 patients with a mean age of 62 years were included within the study. Cases were randomly divided into two groups. group A had undergone 3.5-mm temporal clear corneal phacoemulsification and blood type had undergone 6-mm superior scleral SICS. Surgically induced astigmatism was analyzed by SIA software.

Results: Mean age in A was $61( \pm 8)$ years and in group B was $63( \pm 10)$ years. Mean surgically induced astigmatism in blood group was $1.05( \pm 0.58) \mathrm{D}, 1.13( \pm 0.52) \mathrm{D}, 1.13( \pm 0.56) \mathrm{D}$, and $1.08( \pm 0.52) \mathrm{D}$ on $1^{\text {st }}, 7^{\text {th }}, 21^{\text {th }}$, and $45^{\text {th }}$ postoperative days, respectively. The change from 1st to 45th day wasn't significant. the identical in blood group was $0.75( \pm 0.58) \mathrm{D}, 0.81$ $( \pm 0.54) \mathrm{D}, 0.88( \pm 0.49) \mathrm{D}$, and $0.91( \pm 0.47) \mathrm{D} 1 \mathrm{st}, 7^{\text {th }}, 21^{\text {th }}$, and $45^{\text {th }}$ postoperative days, respectively. Surgically induced astigmatism was comparable on all days between the groups. We found significant with the rule and against the rule form of astigmatism post-operatively within the temporal clear corneal incision in phacoemulsification group and in superior scleral incision in small incision cataract surgery group respectively.

Conclusion: Surgically induced astigmatism was higher within the superior scleral group than in 3.5-mm temporal clear corneal group. Clinical outcome of both surgeries was same, as there was no significant difference within the uncorrected postoperative acuity in between the groups.

Keywords: SIA (surgically induced astigmatism), SICS (small incision cataract surgery), superior scleral incision, WRA (with the role astigmatism) ARA (against role astigmatism). TMC (Tripoli Medical Center).

\section{Introduction}

Cataract surgery has undergone various advances since it absolutely was evolved. It started from ancient couching then transformed to intracapsular cataract surgery and at last evolved to the so called manual phaco technique that's small incision cataract surgery (SICS) finally to modern phacoemulsification cataract surgery. The primary aim may be a good postoperative visual rehabilitation without correction with immediate mobilization, but the most obstacle is surgically induced astigmatism (SIA). Over time, various surgeons have strived hard and invented different incisions to scale back the SIA. the end result of a cataract surgery depends on various factors like incision, approach, variety of surgery, mode of lense (IOL) insertion, and sort of $\mathrm{IOL}^{1}$ The introduction of self-sealing clear corneal incision has gained popularity worldwide because it offers several benefits over

Egyptian Journal of Ophthalmology, a publication of Mansoura Ophthalmic Center.

Address: Mansoura Ophthalmic Center, Mansoura University, Mansoura, Egypt.

Tel. 0020502202064. Fax. 0020502202060.

E-mail: ejo_moc@yahoo.com; tharwatmokbel@yahoo.com 
the normal sutured limbal incisions and scleral tunnel. ${ }^{2}$ Clear corneal incision has advantages of, decreased inflammation and pain, and increased safety similarly as reduced SIA ${ }^{1}$.

Clear corneal wounds have revolutionized cataract surgeries by reducing the surgical time and resulting in faster postoperative recovery as compared to the scleral tunnel approach. Cataract remains the foremost important and significant reason for bilateral blindness in senile people, both in Libya further as worldwide. Modern cataract surgeries with lens (IOL) became one among the safest, simple, and consistent, frequently performed surgeries. Small incision cataract surgery (SICS) is gaining popularity in developing countries as a reasonable alternative to phacoemulsification ${ }^{1}$. SICS and phacoemulsification have advantages like less induced astigmatismand early visual rehabilitation, and no suture-related complications. With advances in technology and predictability of surgery, expectations of both surgeons and patients have increased. Surgeons aim to fulfill the individual patient's refractive goal and patients expect good vision without the spectacles immediately. Postoperative SIA depends on location, size, and architecture of the wound ${ }^{3}$.

The tiny size incision gives a rapid and a stable optical recovery, and thus a lesser $\mathrm{SIA}^{4}$. Many studies were done to check the astigmatism with differing kinds of small incisions in several locations like superior, super- nasal, superotemporal, and temporal. Regarding the architecture of the cornea, giving phacoemulsification incision on the steepest corneal axis at the time of cataract surgery can correct alittle degree of astigmatism. Other options like peripheral corneal relaxing incisions and toric IOLs were also safe and effective for treating considerable degree of preexisting astigmatism. Surprises in refractive errors after cataract surgery became unacceptable in recent few years. As a result, cataract surgery has become refractive surgery offering improvements both in "best corrected" and "uncorrected" visual sense.

Astigmatism by various methods introduced by Alpins and Goggin, ${ }^{3}$ Holladay et al. ${ }^{4}$ and many others. Postoperative astigmatism is affected by various factors such as preoperative astigmatism, location, type, size, closure, and healing of the surgical incision, amount of scleral cauterization performed, type of suturing material used and its placement, position of IOL, and postoperative use of steroids, and all these have effects on corneal curvature. ${ }^{5}$ In 1975, Jaffe and Clayman were first to report surgically induced astigmatism after cataract surgery. In 1975, Jaffe and Clayman first reported the exact measure of change induced by surgery, the SIA. ${ }^{6}$ Now MS Excel sheet-based programs are available that calculate SIA. One such program was used in our study to determine SIA. It used the vector analysis with trigonometry formulas to calculate the SIA. They are also used to predict and modify the surgical skills to reduce SIA according to individuals. ${ }^{7}$

The aim of our study was to document the changes in corneal curvature occurring after cataract extraction over a period of 45 days postoperatively. We planned to compare SIA produced by $3.5-\mathrm{mm}$ temporal clear corneal phacoemulsification and by $6-\mathrm{mm}$ superior scleral incision in SICS..

\section{Patients And Methods}

This was a prospective, interventional, hospital based, observational, follow-up study allotted from July 2013 to September 2017 at university hospital that's Tripoli Medicalcenter at eye department. a complete of 200 eyes of 200 patients with a mean age of 63 years were included within the study. concent was obtained before starting the study. The cases were randomly divided into two groups. One group (group A) had undergone phacoemulsification and therefore the other group (group B) had undergone SICS. Written approval was obtained from all the patients undergoing study.

The inclusion criteria were uncomplicated senile cataract, patients with preoperative astigmatism less then $3 \mathrm{D}$, good fixation, and cataracts up to grade 4 nuclear scleroses. Higher grade of nuclear scleroses was excluded to stay uniformity within the two groups and to stay the incisional architecture uniform and every one posterior chamber lense PCIOLs were placed within the bag. Exclusion criteria were complicated cataracts, traumatic cataract, cataract with glaucoma, uveitis and tumor, cataract related to pterygium, corneal opacity, the eyes which had undergone C3R or LASIK, presenile cataract, zonular dehiscence, and therefore the eyes 
which had undergone previous ocular surgery like scleral tear repair, visual disorder buckling surgery, glaucoma surgery, squint, corneal suturing also eyes which were high myopic and hypermetropic. Preoperative assessment included sight, pressure, sac syringing, and examination of anterior and posterior segments. an intensive posterior segment evaluation was finished $90 \mathrm{D}$.

The grading of nucleus was performed in line with Lens Opacification organisation III (LOCS III). Keratometry was performed preoperatively and postoperatively by using AutoKeratometer. SRK II formula was accustomed calculate the IOL power. Surgical Technique All cases were operated under local peribulbar anesthesia or topical anaesthesia. Under all aseptic precautions, $5 \%$ povidone iodine was instilled within the conjunctival cul-de-sac before surgery. Group A patients underwent phacoemulsification. A $3.5-\mathrm{mm}$ straight Corneal tunnel was made ahead of the vascular arcade.. Anterior chamber was entered with 3.5 keratome. Corneal tunnel was bi-planar and had self-sealing property. Corneal tunnel width was $3 \mathrm{~mm}$. A side port was made. The nucleus was emulsified by stop \&chopping technique. A $5.25-\mathrm{mm}$ optic sized foldable IOL of appropriate power was implanted within the bag all told cases. Stromal hydration of the most incision and site port was done. Wound was water tight by pressing over cornea with a blunt spatula . Group B patients underwent SICS. A 6-mm scleral straight incision was made superiorly, $2 \mathrm{~mm}$ faraway from limbus, with 15 no.

Bard Parker blade. Sclero-corneal tunnel was dissected employing a crescent knife, and also the tunnel width was 1 $\mathrm{mm}$ in clear cornea. Internal incisions were $7 \mathrm{~mm}$ and hydrodissection was performed. Nucleus was brought in anterior chamber (AC) and delivered by visco-expression; PMMA PCIOL was implanted within the bag altogether the cases. Both groups had self-sealing incisions, which thereby prevented the necessity for any suture. There was no attempt made in any case to switch the pre-existing astigmatism. Assessment Postoperatively was done on the $1 \mathrm{st}, 7 \mathrm{th}, 21 \mathrm{st}$ , and 45 th days. At each visit, measurement of visual sense, anterior segment examination, fundoscopy, and keratometry were done. The course of postoperative astigmatic changes determined by keratometry performed with a typical calibrated Topcon auto-keratometer. Corneal clarity, wound integrity, and PCIOL placement were carefully examined on postoperative follow-ups. SIA was calculated by using SIA version 3.1. softwearcalculater [7] SIA was interpreted in magnitude [diopter (D)] and axis (degree).

\{https://www.insighteyeclinic.in/SIA_calculator.php\}
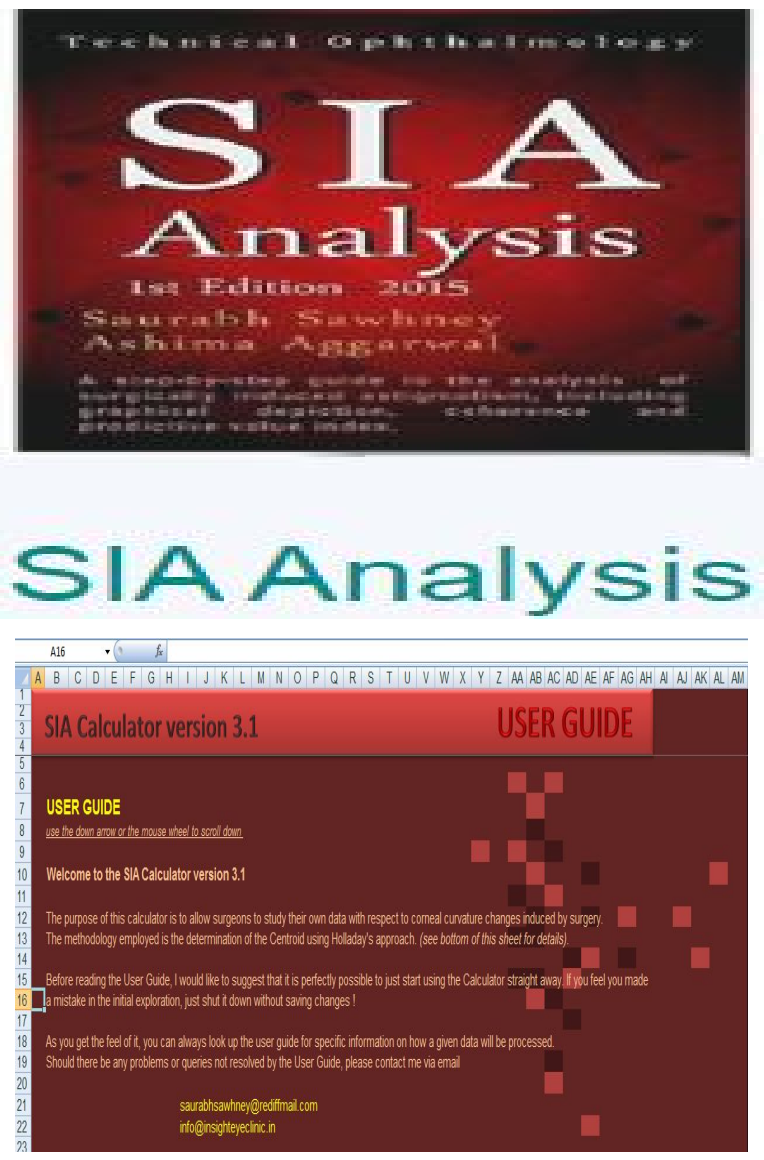

Data analysis was done using the Statistical Package for the Social Science (SPSS) Version 15 for Windows. Z test was used to find significant differences in age, gender, SIA and astigmatism in the study group. Paired t-test was performed for SIA. Chi-square test was used to find the significance among postoperative visual acuity in the study groups. A probability value of 0.05 was accepted as the level of statistical significance. $\mathrm{P}$ value of $<0.05$ was considered statistically significant.

\section{Results}

In this study, 200 eyes of 200 patients were included and underwent cataract surgery at eye dept at Tripoli medical center. They were categorized as group 
A: phacoemulsification with temporal clear corneal incision in 100 eyes and group B: 100 eyes underwent SICS with superior straight scleral incision. The results were analyzed and the following observations were made.

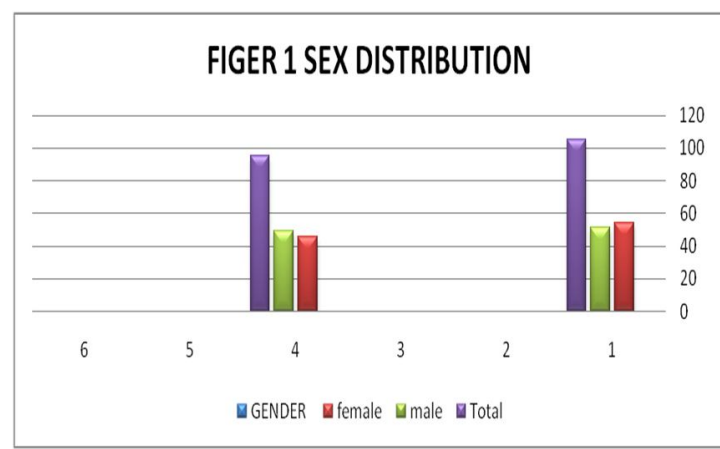

\begin{tabular}{llll}
\hline GENDER & Group A & Group B & Total \\
\hline Female & 54 & 46 & 100 \\
Male & 51 & 49 & 100 \\
Total & 105 & 95 & 200
\end{tabular}

The mean age of the participants was $60.98 \pm 7.83$ years in group A and $62.88 \pm 9.63$ years in group B. There was no significant difference in the incidence of age between group $\mathrm{A}$ and group B. Group A had 54 female patients and 46 male patients. Group B had 49 male and 51 female patients. Both groups were comparable. There was no significant difference between the groups with respect to the laterality of the eye.

Uncorrected postoperative visual acuity was analyzed on the 45 th postoperative day. Three sub-groups were made to analyze the post-operative visual acuity.

There was no statistically significant difference in the uncorrected postoperative visual acuity between the two groups. The two groups were comparable [Table 1].

Table 2a shows comparison of 1st postoperative day SIA to those of 7 th, $21 \mathrm{st}$, and 45 th days. SIA postoperatively showed no statistically significant differences in group A .

Table $2 \mathrm{~b}$ shows comparison of 1 st postoperative day SIA in group B with 7th, 21st, and 45th day SIA postoperatively. It shows no statistical significant difference on 7 th postoperative day, but there was significant difference on $21 \mathrm{st}$ and 45 th postoperative days.

There was statistical increase in SIA from 1 st to 45 th postoperative day. A comparison of SIA between the two groups on $1 \mathrm{st}, 7 \mathrm{th}, 21 \mathrm{st}$, and 45 th days showed a statistically significant difference on all postoperative days [Table 2c]. On comparing the two groups, there was a statistically significant difference between the preoperative and postoperative astigmatism [Table 3] .

Table 1: Comparison of uncorrected postoperative visual acuity on 45th postoperative day in the study groups

\begin{tabular}{llll}
\hline Visual acuity & Group A & Group B & Total \\
\hline 6/60 to 6/24 & 17 & 15 & 42 \\
6/ 18 to 6/ 12 & 61 & 59 & 96 \\
6/9 to 6/6 & 22 & 26 & 62 \\
Total & 100 & 100 & 200
\end{tabular}

Chi-square $=0.49, P>0.05$

Table 2a and diagram: Comparison of postoperative SIA in diopter (D) in group A .

\begin{tabular}{|c|c|c|c|c|}
\hline \multirow[t]{2}{*}{$\begin{array}{l}\text { Postoperative } \\
\text { day }\end{array}$} & \multicolumn{2}{|c|}{$\begin{array}{l}\text { SIA in group A } \\
(n=100)\end{array}$} & \multirow[t]{2}{*}{$t$ Value } & \multirow[t]{2}{*}{$P$ value } \\
\hline & Mean & SD & & \\
\hline 1..day & 1.05 & 0.58 & ZERO & ZERO \\
\hline $7^{\text {th }}$ day & 1.13 & 0.52 & 1.84 & $>0.05$ \\
\hline $21^{\text {th }}$ day & 1.13 & 0.56 & 1.6 & $>0.05$ \\
\hline $45^{\text {th }}$ day & 1.08 & 0.52 & 0.58 & $>0.05$ \\
\hline
\end{tabular}

\section{POST OP days GP A}

Mean po astigmatism

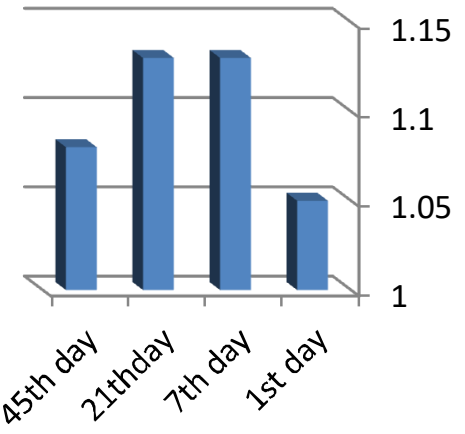


Table 2: Table 2band diagram : Comparison of postoperative SIA in diopter (D) in group B

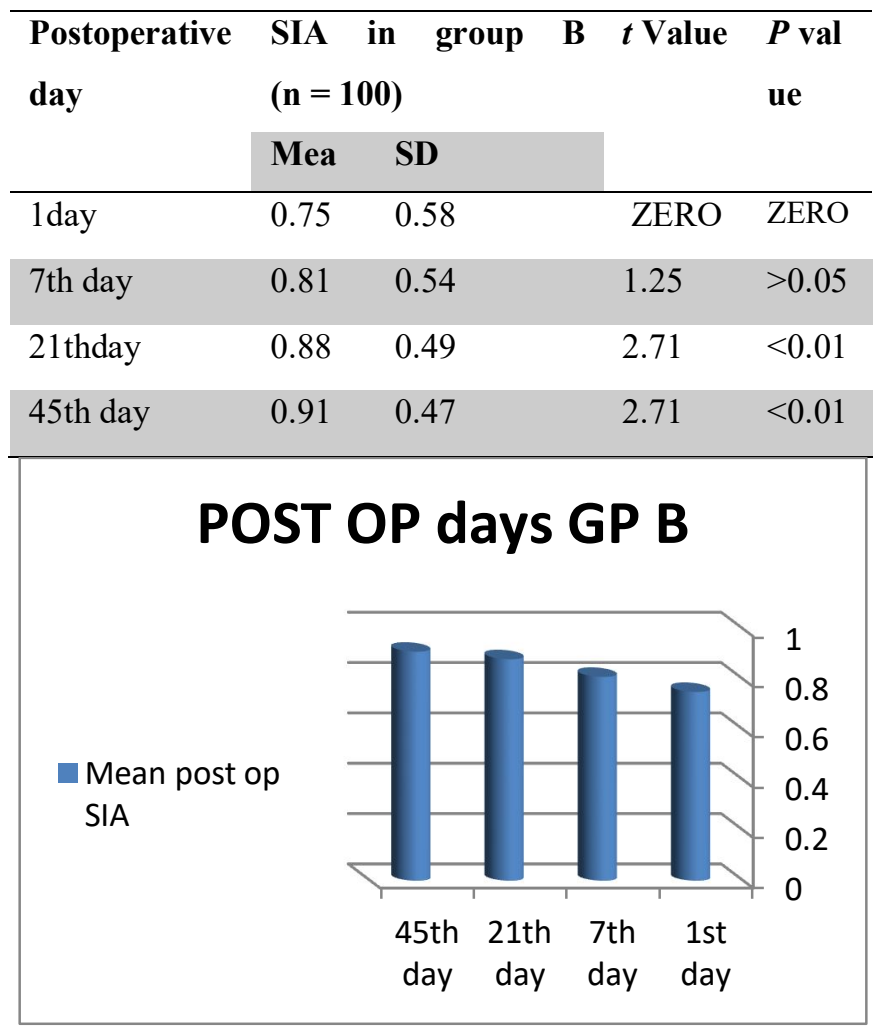

Table 2c: Comparison of SIA on postoperative 1st, 7th, 21st, and 45 th days in the study groups

\begin{tabular}{|c|c|c|c|c|c|c|}
\hline \multirow[t]{2}{*}{$\begin{array}{l}\text { Postoperative } \\
\text { day }\end{array}$} & \multicolumn{2}{|c|}{$\begin{array}{l}\text { SIA in group } \\
\text { A }(\mathbf{n}=\mathbf{1 0 0})\end{array}$} & \multicolumn{2}{|c|}{$\begin{array}{l}\text { SIA in group } \\
\text { B }(n=100)\end{array}$} & \multirow[t]{2}{*}{$\begin{array}{l}Z \\
\text { value }\end{array}$} & \multirow[t]{2}{*}{$P$ value } \\
\hline & Mean & SD & Mean & SD & & \\
\hline 1..day & 1.05 & 0.58 & 0.75 & 0.58 & 3.66 & $<0.005$ \\
\hline 7 th day & 1.13 & 0.52 & 0.81 & 0.54 & 4.27 & $<0.0001$ \\
\hline $21^{\text {th }}$ day & 1.13 & 0.56 & 0.88 & 0.49 & 3.36 & $<0.005$ \\
\hline $45^{\text {th }}$ day & 1.08 & 0.52 & 0.91 & 0.47 & 2.43 & $<0.05$ \\
\hline
\end{tabular}

Table 3: Comparison of type of astigmatism in the study groups

\begin{tabular}{lllll}
\hline $\begin{array}{l}\text { Type of } \\
\text { astigmatism }\end{array}$ & $\begin{array}{l}\text { Group } \\
\text { A }\end{array}$ & $\begin{array}{l}\text { Group B } \\
(\mathbf{N = 1 0 0})\end{array}$ & $\begin{array}{l}\text { Chi- } \\
\text { squar } \\
\text { e }\end{array}$ & P value \\
\hline Preoperative & & & & \\
\hline ATR & 55 & 73 & 8.85 & $<0.0001$ \\
WTR & 26 & 20 & & \\
NA & 19 & 7 & & \\
Postoperative on 45th day & 24 & 91 & 92.19 & $>0.0001$ \\
ATR & 73 & 8 & & \\
WTR & 3 & 1 & & \\
NA & & & &
\end{tabular}

\section{Discussion}

Patients undergoing cataract surgery expect clear vision and fewer dependence on spectacles. to realize this goal, SIA should be reduced. Modern cataract surgery aims at this modification. The rationale behind the current study was little information available on SIA after 3.5-mm temporal clear corneal phacoemulsification surgery. SIA was the most aim of this study, Astigmatism was assessed by using keratometry readings and SIA was calculated with SIA Soft Microsoft Excel sheet calculator.

On comparing the sort of astigmatism postoperatively, we found a big change to with the rule (WTR) astigmatism after temporal clear corneal incision and to against the rule (ATR) astigmatism within the superior scleral SICS. In our study, no oblique astigmatism was encountered. The difference was accused to the traction force of eyelid blinking on superior wound. The change within the corneal curvature is accountable for SIA and also the astigmatic refractive error. Uncorrected astigmatism can cause blurred images and glare that leads patient discomfort and dissatisfaction with otherwise uneventful cataract surgery ${ }^{7}$.

Length of incision and site are the 2 major factors affecting the induced astigmatism. We compared two sizes and sites, one for SICS 6-mm scleral incision and therefore the other for phacoemulsification group 3.5-mm clear corneal incision. Many studies document temporal clear corneal incision of $2.75,3.25$, and $4.1 \mathrm{~mm}$, which are astigmatically neutral eyes and people with low preoperative WTR astigmatism. So, horizontal meridian incisions have a plus of less SIA as they're far from the visual axis ${ }^{9-13}$.

Postoperative visual sense was monitored on all postoperative day follow-ups in both groups, and also the results were analyzed on the 45 th postoperative day. Both the groups had similar sharp-sightedness. There was no significant difference between the 2 groups. This was supported by the difference of SIA within the two groups on the 45 th postoperative day. Difference in SIA was statistically significant, but there was a negligible difference between the 2 groups. SIA in type A was $1.08( \pm 0.52)$ and in type B was $0.91( \pm 0.47)$ on the 45 th postoperative day. 
Further studies are required to search out its efficacy and advantages over other kinds of incisions, both in SICS and phacoemulsification. Follow-up time was too short (45 days) and a extended follow-up is required for the observation of changes in astigmatism and decay within the induced astigmatism over time because the wound heals. Videokerotography wasn't performed. Temporal clear corneal incision caused a minimal change within the kind of astigmatism and superior scleral incision induced a big ATR astigmatism postoperatively. SIA in phacoemulsification group was slightly more than SICS group. But the clinical evaluation proved that postoperative uncorrected visual outcome was same in both the groups. Clinically it's proved that the results of both $3.5-\mathrm{mm}$ temporal clear corneal incision and 6-mm scleral incision are comparable and either of the incisions are often used while performing successful cataract surgery.

There are several variables which affect the amount of surgically induced astigmatism. These are mainly, location (corneal, limbal or scleral), direction (superior, temporal or supero-temporal), width, depth and shape of the incision. The depth of incision has been reported to have little influence on the amount of induced astigmatigm. On the other hand, location and direction of wound has a significant effect on the outcome. With the rule astigmatism is produced when the corneal curvature is steepest in vertical meridian. Conversely, against the rule astigmatism is present when the steepest meridian of cornea is horizontal. Superior meridian incision produces greater 'against the rule astigmatism'. It is found more in elderly patients. Whereas, temporal incision produces 'with the rule astigmatism'. It results in better uncorrected visual acuity ${ }^{14-20}$.

\section{Corresponding author}

Correspondence to Greeb Abagdadi

Email:

\section{Affiliations}

Greeb Abagdadi

Department of Ophthalmology, Faculty Of Medicine, Tripoli University -2021

\section{Ethics declarations \\ Conflict of interest}

Gamal Ali Bennaser, Ghareeb Albaggdadi, Mansur Janeef, all authors have no conflicts of interest that are directly relevant to the content of this review.

Funding: No sources of funding were used to conduct this review.

Reviewer disclosures: No relevant financial or other relationships to disclose.

Declaration of interest: No financial affiliations or financial involvement with any organization or entity with a financial competing with the subject matter or materials discussed in the review.

\section{Financial disclosure}

None of authors have any proprietary interests or conflicts of interest related to this submission.

None of the authors received any financial support during this work.

This submission has not been published anywhere previously and that it is not simultaneously being considered for any other publication.

\section{References}

1. Venkatesh R, Das M, Prashanth S, Muralikrishnan R. Manual small incision cataract surgery in eyes with white cataracts. Indian J Ophthalmol 2005;53:173-6.

2. Malik KP, Goel R. Post-operative astigmatism in cataract surgery. Ophthalmol Today 2001:96-7.

3. Alpins NA, Goggin M. Practical astigmatism analysis for refractive outcomes in cataract and refractive surgery. Surv Ophthamol 2004;49:109-22.

4. Holladay JT, Moran JR, Keririan GM. Analysis of aggregate surgically induced refractive change, prediction error and intraocular astigmatism. J Cataract Refract Surg 2001;27:61-78.

5. Spierer A, Bar-Sela SM. Change in Astigmatism after cataract surgery and intraocular lens implantation. Arch ophthalmol 2004;122:695-7.

6. Basak SK, Basak S, Chowdhury AR. 'SIA-Soft': A new software to calculate surgically induced astigmatism 
in comparision with manual mathematics vector metod. Indian J Ophthalmol 2008;56:170.

7. Available from: http://www.ieseyecare.com/ [Last accessed on 30 August 2013]

8. Reddy B, Raj A, Singh VP. Site of incision and corneal astigmatism in conventional SICS versus phacoemulsification. Ann Ophthalmol (Skokie) 2007;39:209-16.

9. Marek R, Klus A, Pawlik R. Comparison of surgically induced astigmatism of temporal versus superior clear corneal incision. Klinika Oczna 2006;108:392-96.

10. Pakravan M, Nikkhah H, Yazdani S, Shahabi C, SedighRahimabadi. Astigmatic outcome of temporal versus nasal clear corneal phacoemulsification. J Ophthalmics Vis Res 2009;4:79-83.

11. Borasio E, Mehta JS, Maurino V. Surgically induced astigmatism after phacoemulsification in eyes with mild to moderate corneal astigmatism: Temporal versus onaxis clear corenal incisions. J Cataract Refract Surg 2006;32:565-72.

12. Pfeger T, Skorpik C, Menapace R, Scholz U Long term course of induced astigmatism after clear corneal incision cataract surgery. Cataract Refract Surg 1996;22:72-7.

13. Kohnen T, Dick B, Jacobi KW Comparision of the induced astigmatism after temporal clear corneal incision of different sizez. J Cataract Refract Surg 1995;21:41724.

14. Jurowski P. Reasons of postoperative astigmatism. Klin Oczna. 2003;105:82-5.

15. Malik KPS, Goel R. Small incision catSmall incision cataract surgery: An introduction in Manual of Small incision Cataract Surgeryaract surgery: An introduction in Manual of Small incision Cataract Surgery. 1st ed. New Delhi: CBS Publishers \& Distributors; 2003

16. Ravindran R, Aravind H, Minu M. Relevance and clinical significance of SICS (Manual Phaco) in Modern Cataract Surgery. In: Garg A, Fry L, Tabin G, Guiterrez-Carmona F, editors. Clinical Practice in Small Incision Cataract Surgery. United Kingdom; 2004. by 17 . Yorston D, Foster A, Wood M, Foster A. Does prospective monitoring improve cataract surgery outcomes in Africa? Br J Ophthalmol. 2002;86:543-7.

18. Holladay JT, Dudeja DR, Koch DD. Evaluating and reporting astigmatism for individual and aggregate data. J Cataract Refract Surg. 1998;24(1):57-65.

19. Kimura H, Kuroda S, Mizoguchi N, Terauchi H, Matsumura M, Nagata M. Extracapsular cataract extraction with a sutureless incision for dense cataracts. J Cataract Refract Surg . 1999;25(9):1275-9.

20. Berger BB, Emery JM, Peyman GA. The Lens, cataract and its management. In: In peyman, Sanders and Goldberg(ed): Principles and practice of Ophthalmology . vol. 1. India: Jaypee Bros; 1987. p. 393. 